\title{
Opioid Addicted Pregnancies: A Public Health Issue
}

\author{
James F. Anderson ${ }^{1}$, Kelley Reinsmith-Jones ${ }^{2}$, Laronistine Dyson ${ }^{3}$, Adam H. Langsam ${ }^{4}$ \\ ${ }^{1}$ College of Arts and Sciences, Professor of Criminal Justice, East Carolina University, Greenville, NC, USA \\ ${ }^{2}$ College of Health and Human Performance, Associate Professor of Social Work, East Carolina University, Greenville, \\ NC, USA \\ ${ }^{3}$ National Association of Women-OSB, Director of Marketing and Membership, Atlanta, GA, USA \\ ${ }^{4}$ College of Liberal Arts, Professor of Sociology, Northeastern State University, Tahlequah, OK, USA \\ Correspondence: James F. Anderson, Professor, Department of Criminal Justice, East Carolina University, Greenville, NC, \\ USA.
}

Received: August 10, 2018

doi:10.11114/ijsss.v6i9.3609

\author{
Accepted: August 28, $2018 \quad$ Available online: September 7, 2018
}

URL: https://doi.org/10.11114/ijsss.v6i9.3609

\begin{abstract}
While the opioid crisis in the US has been widely publicized, what has not been given equal attention is the increasing number of pregnant women addicted to various prescribed and illegal opioids which has paralleled the current opioid epidemic. Instead of viewing the matter as a criminal justice issue, many experts believe that the issue is a public health problem because of the sheer number of people who are impacted nationwide, as well as the negative health consequences that affect the mothers and infants. We argue that opioid addicted pregnant women is not a criminal justice issue, but rather, a public health epidemic that requires healthcare approaches rather than punitive criminal justice strategies.
\end{abstract}

Keywords: opioids, epidemic, drug abuse, public health approach, neonatal abstinence syndrome, pregnant addicts

\section{Introduction}

Recently, the Centers for Disease Control and Prevention (CDC), reported that opioid abuse in the US had reached epidemic proportions. More specifically, the $C D C$ revealed that since 2015, there has been more than 33,000 deaths related to opioids, and another 91 people die each day because of opioid overdoses (Reddy et al., 2017). It also provides that the opioid crisis has been exacerbated because opioid prescriptions have quadrupled since 1999 making highly addictive drugs readily available (Rudd et al., 2016). But, why have opioids become so desirable? Pharmacologists argue that opioids are a classification of both natural and synthetic compounds that bind specific opioid receptors in the central nervous system to send messages to relieve pain, and in many cases, leave users with feelings of euphoria (Craig et al., 1994; Harvey et al., 1992). Nevertheless, vital statistics indicate that from 2000 to 2014, opioid related overdoses among adult Americans have increased by $200 \%$ (Rudd et al., 2016). Along with the increase in prescription opioid abuse, came a corresponding rise in heroin use, abuse, and overdose deaths $(C D C, 2016)$. In addition, health experts noticed that by 2010 , the socioeconomic and demographic characteristics of opioid addicts had changed in the US. According to Cicero and colleagues (2014), the majority of addicts that entered treatment programs were typically middle-class women who live in less urban or rural areas and over $90 \%$ were white. Nevertheless, while most people in the US are aware of the current opioid crisis, very few may know about the growing number of pregnant women who are addicted to opioids (including heroin) (Desai et al., 2014; Krans et al., 2015). More specifically, health experts argue that while efforts are made to inform the public about the dangers of opioids, more emphasis should be placed on one particular subset of the addicted population of users. In fact, health officials at the $C D C$ provide that a large number of reproductive-aged women are at risk of developing opioid use disorder stemming from either prescription or illegal opioids since researchers revealed that over two-thirds (or roughly 66\%) of pregnant women on medication-assisted treatment, and approximately $63 \%$ report a history of heroin use and intravenous heroin use, respectively (see Krans et al., 2015). Consequently, and more alarming is the fact that their newborns face serious health injuries associated with opioid abuse, namely drug withdrawal or Neonatal Abstinence Syndrome (NAS) (Reddy et al., 2017; Klaman et al., 2017; Patrick and Schiff, 2017).

Health experts warn that in addition to other opioid addicts, the number of pregnant addicts has increased (Desai et al., 
2014; Patrick et al., 2015). Some studies reveal that many women who were unaware of their pregnancy, later reported using various opioids. As a result, they unknowingly exposed their newborns to birth defects and themselves to serious harm (see Farst, Valentine, \& Hall, 2011). Ko and colleagues (2017, p242), report that opioid exposure during pregnancy can occur for several reasons that include: use of clinically-approved prescriptions of opioids for pain relief, misuse or abuse of prescription opioids, use of illegal drugs (namely, heroin), or medication-assisted treatment of opioid use disorder (also see ACOG, 2012). Because scant attention has been devoted to pregnant opioid addicts, this investigation is divided into four parts. Part One presents the nature and extent of pregnant opioid addicts in the US. Part Two addresses why pregnant opioid addiction is a public health, rather than a criminal justice issue. Part Three offers prevention and treatment approaches to this growing epidemic. Part Four presents viable policy implications. In the final analysis, we argue that the use of public health or epidemiological approaches to treat this special population of opioid addicts is more effective at reducing the negative health consequences associated with this addiction.

\section{The Nature and Extent of Opioid Addicted Pregnancies}

Research shows the number of opioid addicted pregnant women has skyrocketed and reached the point of crisis in the US, especially in the last decade, leading health officials to label the matter an epidemic (Krans and Patrick, 2016; Patrick and Schiff, 2017). As such, public health experts estimate that between 400,000 and 440,000 infants are negatively affected by prenatal alcohol or illegal drug exposure that often leads to health problems (Cohen, 2017; Swanson, 2014). Correspondingly, studies report that every 25 minutes, a drug addicted baby is born in the US (Cohen, 2017). Moreover, Desia and colleagues (2014), research reflects that records from Medicaid enrolled women show an increase in the percentage of pregnant women who filled at least one opioid prescription (Also see Ailes et al., 2015). Furthermore, Reddy and colleagues (2017, p10), find that approximately one third of insured reproductive-age women (e.g., between the ages of 15 and 44) fill a prescription for an opioid medication annually, while a woman seeks care in an emergency room for misuse of prescription opioids every three seconds in the US (see also $C D C$, 2017). Ailes and colleagues (2015, p37), present a more persuasive argument by reporting that between 2008 and 2012, an average of 39\% of Medicaid insured, and $28 \%$ of privately insured women of reproductive-ages filled an outpatient prescription for an opioid each year. These patients with prescriptions were disproportionately non-Hispanic whites living in the southern states. Accordingly, they argue that the over prescribing of opioids that began in the latter 1990s, led to the escalation of use among pregnant women (Ailes et al., 2015). Moreover, reports reveal an increase in opioid use among pregnant women from 2000 to 2010 by an estimated $23 \%$ from $18.5 \%$ to $22.8 \%$. Likewise, research by Maeda and colleagues (2014), focused on the prevalence of opioid abuse among pregnant women, revealed an increase from 1.7 per 1,000 delivery admissions in 1998 to 3.9 in 2011. Strikingly similar to these statistics, Swanson (2014), and the CDC (2016), reported that the use and misuse of opioids (e.g., codeine, hydrocodone, fentanyl, morphine, opium, methadone, oxycodone, meperidine, hydromorphone, propoxyphene, and buprenorphine) by pregnant women underwent a dramatic increase from 1.2 per 1000 hospital live births in 2000 to 5.6 in 2009, while NAS incidences increased from 1.2 to 3.4 per hospital live births (also see Patrick et al., 2015; Patrick et al., 2012).

Another study reported that opioid use among pregnant women resulted in an alarming $400 \%$ nationwide increase in $N A S$ cases and other health complications. More specifically, where $N A S$ is concerned, data revealed an increase from 1.2 per 1,000 hospital births in 2000 to 5.8 in 2012, while some states reported rates that exceeded 30 per 1,000 hospital births. However, by 2012, medical records from several states showed on average, one NAS affected baby was born every 25 minutes in the US (see Patrick et al., 2015; Also see Ko et al., 2016). Furthermore, Swanson (2014), cited two studies that reported opioid use and abuse has been on the rise among pregnant women. The first revealed that $23 \%$ of 1.1 million pregnant women on Medicaid filled an opioid prescription in 2007. This represented an increase from $18.5 \%$ in 2000 . The second reported that $14 \%$ of privately insured pregnant women also filled a prescription for opioids. Swanson (2014), contends that what is more alarming about doctors prescribing pain medications to pregnant women is the fact these doctors are aware that they may cause birth defects.

Ailes and colleagues (2015), provided demographic data on reproductive-aged women with outpatient claims for using either private or Medicaid service for an opioid prescription during 2008-2012. These data focused on variables such as age group, geographical region (only available for privately insured women), and race and ethnicity (only available for Medicaid enrolled women). More specifically, with respect to those privately insured, from 2008-2012, between ages 15-19, the average was 20.4. Recipients between ages 20-24 average was 23.8. Those between ages 25-29 average was 29.6. Those between ages 30-34 average was 30.9. Recipients between ages 35-39 average was 30.4, while those between ages 40-44 average was 29.9. Where geographical region is concerned for the same period (2008-2012), recipients in the Northeast average was 21.8. Those in the North central average was 25.4. Those from the South average was 31.5. Those from the West average was 26.6, and the unknown regions comprised 27.3. Data regarding race and ethnicity was not available for those who were privately-insured. By comparison, data on those who received Medicaid during 2008-2012, revealed that the average was 25.9 for those ages 15-19. Recipients between ages 20-24 
had an average of 41.7. Those between ages 25-29 average was 46.6. Those between ages 30-34 average was 48.7. Recipients between ages 35-39 average was 50.6, while those between ages 40-44, average was 52.5. Data on geographical region were not available for those who received Medicaid. However, data regarding race and ethnicity for the same period (2008-2012), revealed that Whites, non-Hispanic average was 46.4. Blacks, non-Hispanic average was 35.2. Hispanics average was 33.6, and Others average was 28 . Stated differently, data confirm that women of all races and ethnicities that lack private insurance are impacted by the opioid crisis.

\section{Pregnant Opioid Addicted Mothers: A Criminal Justice or Public Health Issue}

\subsection{A Criminal Justice Issue}

While public health officials view opioid addiction as a disease that should be treated, law enforcement officials, and other criminal justice practitioners, see drug use as a violation of the criminal law that must be punished (see Gaines and Kraska, 1997; Tonry and Wilson, 1990). Therefore, many in the justice system believe that opioid users should be convicted under existing drug and child abuse laws, and then receive a prison sentence at an appropriate correctional facility (Peak and Everett, 2017). More specifically, justice officials believe that when addicted mothers expose unborn children to illegal drugs, it constitutes either felony aggravated assault; causing harm to an unborn fetus; engaging in the chemical endangerment of a child, or when the fetus dies, a homicide (Paltrow and Flavin, 2013). However, states vary with respect to which charges it will file against the accused. Nevertheless, most states view drug use during pregnancy as grounds for sentencing the mother to a term of imprisonment. Other states may justify involuntary detainment for inpatient treatment, and some states may even impose civil commitment (Vestal, 2017). Most justice critics view these reactions as ways that states punish mothers and children (Cohen, 2017). Despite the current opioid crisis, and the corresponding number of pregnant women who engage in substance use disorder of legal or illegal opioids, most states typically respond in a punitive way.

Justice experts believe that prosecuting and incarcerating pregnant opioid users will deter them, and others, from using (Hunter, 2017; Patrick and Schiff, 2017). Critics ponder whether this means that the mothers of the estimated 440,000 babies born addicted to drugs each year will be arrested and held criminally responsible. The same group argues that this approach will not achieve deterrence, but rather, will cause the opposite effect (Roberts and Nuru-Jeter, 2010). Nevertheless, justice officials advocate the criminalization of drug users without regard to their pregnancy status. However, they argue that being an addict (e.g., the status of addiction) is not criminalized, but instead, the behaviors that addicts engage in such as buying, receiving, and exposing unborn babies to drugs that could cause birth defects, chemical shock from opioid withdrawal, or an untimely death, constitutes criminal law violations. On the contrary, those with opposing views, argue that this approach exacerbates the problem and discourages addicted pregnant women from seeking prenatal care or substance abuse treatment since they fear arrest, detention, and prosecution (Peak and Everett, 2017; Patrick and Schiff, 2017). As such, reports show that the fear of punishment, along with the prospect of losing a newborn, have frightened many addicted pregnant women to the point where they avoid visiting hospitals, and instead, are having babies at home, in cars, and on the side of the road. These critics believe that this trend will likely continue since an estimated forty-five states require mandatory reporting (to police and child protective services) if drug use is detected from tests taken by pregnant women, or if babies are born addicted to opioids (Hunter, 2017; Cohen, 2017).

\subsection{Efforts toward Massive Confinement}

Correctional statistics reveal that despite a slight decline (0.9\%) in its prison population, the US is still the most punitive nation among advanced societies since it incarcerates and provides supervision to an estimated 6,613,500 Americans annually. This includes pregnant women, some of whom have extensive histories of substance abuse (Kaeble and Cowling, 2018; Krisberg, Marchionne, \& Hartney, 2015; Seiter, 2014). Many offenders are housed in the nation's jails and prisons, while the vast majority of offenders are given community supervision (e.g., probation or parole). Some scholars argue that many incarcerated offenders are residual leftover from the crack cocaine war fought during the 1980s and 1990s which has contributed significantly to prison overcrowding (see Messner and Rosenfeld, 2013; also see Mauer, 2006). Similarly, experts fear the current opioid crisis, combined with many states' punitive stance on pregnant opioid users, will add to an already strained correctional system (e.g., sentencing more addicted pregnant offenders to prison) that claims to be seeking strategies to alleviate overcrowding problems through criminal justice reforms. Observers note that talk of criminal justice reform has not resulted in legislation to decongest the nation's overcrowded places of confinement. Currently, most states regard pregnant opioid addicts as offenders who committed assault on their unborn child and consequently, deserve punishment, rather than treatment for their addiction (Patrick and Schiff, 2017). It bears mentioning that offenders who are sentenced by the justice system and remanded to institutional corrections (e.g., jails and prisons), are sent to places that focus on meting out punishment instead of providing treatment. Some justice scholars argue that this may explain the high rates of recidivism since it is unlikely 
that offenders will receive treatment for opioid or any other chemical dependency. Moreover, the alternative form of corrections is community-based. It is unlikely and unwise that addicted offenders will be released back into the free community where they will have easy access to illegal drugs. Therefore, critics argue the justice system is not designed for drug treatment or to provide the level of medical care needed by offenders in general, and pregnant women and their unborn children, in particular.

\subsection{Confined Women and Healthcare}

The need for substance abuse treatment for confined women is well-documented in the criminal justice literature since research shows that an estimated $49 \%$ have serious histories and problems with alcohol and substance abuse prior to incarceration (Calhound et al., 2010; Krisberg, Marchionna, \& Hartney, 2015; Bloom and Owen, 2002). Similarly, Mumola and Karberg (2004), reported that 59\% of female state prisoners admitted to using drugs within a month of committing their offense. Moreover, 17\% reported using methamphetamines in the month of their crime. Likewise, Green and Snell (1999), reported that $40 \%$ of women were under the influence of drugs at the time they committed their crime. Some experts argue that many women who commit crime often come from abusive backgrounds which invariably leads them to drug abuse and addiction as a coping mechanism (Covington, 2007). To further highlight the point, a nation-wide study found that one in three women in state prisons reported that they committed the crime that landed them in prison to get money needed to defray the cost of their drugs. Notwithstanding, an investigation conducted in Maryland by the Center for Substance Abuse Treatment (1997, p2), reported that nearly $80 \%$ of the women in state prisons have "severe, long-standing substance abuse problems." These findings reveal that women in prison need substance abuse treatment programs. While some prisons offer drug programs, research consistently shows that they are inadequate, unsatisfactory, and highly ineffective since many women offenders often recidivate after release owing to committing a drug offense. Furthermore, Stephan (2008), reported that while $74 \%$ of all prisons offered drug and alcohol counseling in 2002, only $12.9 \%$ of the prison population participated in drug treatment programs. Similarly, Karberg and James (2002), reported that only $20 \%$ of women offenders reported receiving drug treatment during their incarceration. A later follow-up by Scroggins and Malley (2010), revealed that women prisoners are still not receiving needed treatment programs while incarcerated. Consequently, as part of their post-incarceration, they typically are placed in substance abuse programs that are often insufficient to help them successfully reenter society. Because of this, some justice scholars have advocated an increase in more and better-quality treatment programs for women in and outside of prisons. Research by Chesney-Lind and Pasko (2004), and Patrick and Schiff (2017), is instructive in this regard. Their work suggests that substance abuse treatment programs must be gender specific and focus on strategies that address women's substance abuse problems.

While nearly every state in the country is affected by the current opioid epidemic, research shows that North Carolina has been one of the most adversely impacted by this crisis. Therefore, it offers a timely as well as realistic example of the economic devastation that some states are experiencing since experts report that in 2014, the total costs of the opioid crisis to North Carolina reached an estimated $\$ 2$ billion: \$582 million in health care costs from opioid abuse, and \$1.5 billion in loss of future productivity and medical costs from overdose deaths (Hunter, 2017). Furthermore, North Carolina spends an estimated $\$ 32,594$ annually to incarcerate offenders. With the influx of more opioid addicts being brought into the justice system (including pregnant women), this will invariably cost the state more monies to support its public health as well as criminal justice systems. North Carolina can be an example to other states that are being confronted with the opioid epidemic.

\subsection{A Public Health Issue}

The increase in opioid addicted pregnant women is a public health issue because of the negative health consequences associated with the behavior. As stated earlier, the $C D C$, along with other health professionals, have labeled the matter an epidemic that should be addressed by the healthcare professionals, and not criminal justice officials for two reasons. First, opioid abuse is a serious public health problem because the number of addicts has reached epidemic proportions (with it a host of health concerns that could impact the population at-large). Second, opioid addiction is a disease that must be addressed by trained medical professionals. More specifically, health officials argue that agents of the justice system are experts at arresting, charging, and punishing offenders, but not at making medical diagnoses, providing medical treatment, and monitoring opioid addicts since they lack medical training, expertise, and the resources needed to adequately treat the effects that prescription and illegal opioids have on pregnant women and their unborn children which typically include: Opioid use disorder (OUD), NAS, HIV/AIDS, Hepatitis C, and other infections common to intravenous drug users $(C D C, 2015)$. Because more people could be exposed to these and other diseases that can quickly spread throughout the community, the effects of opioid addiction are a public health issue. Stated differently, the consequences of opioid addiction (prescribed or illegal) in general, and to pregnant women and their unborn children, in particular, transcends the scope, expertise, and resources of the justice system because they are far reaching and could have negative health consequences on the broader community and society. 


\subsection{Opioid Use Disorder (OUD)}

Research shows that OUD has reached the point of crisis in the US (Bianchi, 2017; Patrick and Schiff, 2017). Health professionals argue that the problem is more likely to increase in the future. Therefore, they suggest that efforts should be made to treat and manage these conditions. They also argue that more research should be conducted to identify and improve the health outcomes of opioid addicted pregnant women and their new born infants. More specifically, health experts recommend that pregnant women receive routine screening for substance use, including misuse of prescription and illegal opioids (namely, heroin) throughout their pregnancy. They also suggest as a matter of standard therapy for opioid addicted pregnant women that medical experts (because these medications are considered low risk and will improve compliance to prenatal care), consider opioid replacement therapy such as methadone or buprenorphine to manage withdrawals, reduce cravings, and prevent illicit opioid use, as well as provide medical supervision for withdrawal (Bianchi, 2017).

\subsection{Neonatal Abstinence Syndrome (NAS)}

NAS is a hidden consequence of the opioid crisis (Ko et al., 2017). It occurs in women who use opioids during pregnancy. Moreover, being addicted to opioids and pregnant increases the likelihood that NAS and other health complications will surface (Patrick and Schiff, 2017; Brocato, 2015). Health experts define NAS as a drug withdrawal syndrome that typically occurs in infants after in-utero exposure to opioids. Some research shows that it appears within 2 to 3 days after birth and reveals itself with adverse impact on the central and autonomic nervous systems via irritability, gastrointestinal dysfunction, and temperature instability (Ko et al., 2017; Reddy et al., 2017; Bagley et al., 2014). Other studies suggest the effects often include: tremors, diarrhea, incessant crying and irritability, along with problems sleeping, feeding, and breathing (Bianchi, 2017; Brocato, 2015). Unfortunately, some other health issues NAS babies experience are respiratory problems, feeding abnormalities, low birth weight, and seizures that are very costly to parents, as well as hospitals. This is especially true for neonatal intensive care units (Ko et al, 2017). In fact, experts estimate that in 2012, children born with $N A S$ cost hospitals an estimated $\$ 1.5$ billion with approximately $80 \%$ paid for by Medicaid programs. Consequently, public health officials argue that steps must be taken to prevent and treat pregnant opioid addicted women before and during pregnancy in order to reduce incidence of $N A S$ and prevent its economic impact on the health care system. They also suggest opioid exposure during pregnancy could occur for many reasons that include: clinician-approved prescriptions given for pain relief; treatment given to opioid addicted mothers for prescription opioid, illegal use of opioids (e.g., heroin), or from medication-assisted treatment for opioid use disorders (Bianchi, 2017; Ko et al., 2017, p242).

\subsection{HIV/AIDS and Hepatitis $C(\mathrm{HCV})$}

Statistics also reveal other health concerns that opioid addicted pregnant women could face. Data reveal increasing numbers of pregnant women who contract HIV/AIDS and Hepatitis $C(H C V)$ from engaging in high risk behaviors such as sharing contaminated syringes or having unprotected sex with others who are infected with these and other infectious diseases (Alcabes and Friedland, 1995; Steedman and Younoussi, 2000). Health experts report the former typically occurs when addicts inject illegal opioids such as heroin. Nevertheless, McCance-Katz (2011), reports that caring for pregnant women with HIV/AIDS who also suffer from co-occurring substance abuse, presents a medical challenge since effective clinical care requires interventions that must focus on both the physiological changes of the women, and the needs of their developing fetus. This is vitally important since opioid dependent women need opioid therapies (such as methadone or buprenorphine). These women also face the risk that drug interactions with some HIV medications could cause adverse effects that led to negative outcomes. Further, McCance-Katz provides that the main goals of treatment are twofold. First, to ensure a safe pregnancy for the women. Second, to avoid fetal toxicity by delivering babies that are free of $H I V$. Health experts argue that such goals require aggressive treatment to the $H I V$ in order to decrease rival load, or prevent transmission to the fetus, as well as protect the mother from any infections owing to immune deficiencies induced by HIV (Also see McCance-Katz et al., 2009). Moreover, Jones and colleagues (2005), report that opioid addicted pregnant women should be treated at methadone maintenance treatment programs to protect them from complications associated with injection drug use. These researchers recommend that these pregnant women be given buprenorphine because studies report that it has fewer adverse effects and is linked to fewer cases of severe NAS than methadone (ACOG, 2012).

\subsection{Epidemiological Approaches to Public Health Issues}

Public health officials use the epidemiological approach which consists of health-event surveillance, epidemiological analysis, intervention design, and evaluation to prevent illnesses and injuries (Schneider, 2011). Because of past successes with treating and curing diseases and injuries, officials at the $C D C$ are confident that the epidemiological approach can also be successful at preventing and curing the increasing population of opioid addicted pregnant women. Again, opioids are defined as a class of drugs that includes illicit heroin, but also prescription pain relievers (National Institute of Drug 
Abuse, 2015). The epidemiological approach employs a multi-disciplinary approach to study and prevent diseases and injuries that adversely impact the population. Because of the complexities of diseases and injuries, the approach draws on the resources of multiple disciplines to better understand and address the issues of drug use, addiction, and in this case, how they impact pregnancy. Some disciplines used in the epidemiological approach include: biomedical sciences; environmental health sciences; social sciences; and the behavioral sciences (Schneider, 2011).

As a strategy, epidemiologists rely on public education campaigns to reach millions of Americans who often represent a captive audience. As such, they use television, radio, and billboards to inform and educate people about pressing health concerns (Schneider, 2011; Rosenberg and Fenley, 1991). They provide information on disease prevalence and incidences, where to seek treatment and help for (in this case) opioid addiction (from either prescription painkillers, or heroin) used by pregnant women. Moreover, this approach allows public health officials to treat diseases and injuries as epidemics when many people in the population are affected. For example, Cohen (2017), and Swanson (2014), reported an estimated 400,000 to 450,000 babies are born addicted to opioids. Relying on the epidemiological approach enables public health officials to mobilize resources in medicine, mental health, social sciences, and substance abuse services to prevent injuries and death (Rosenberg and Fenley, 1991). Medical experts argue that this approach is a radical departure from strategies used by the criminal justice system to control crime. Therefore, epidemiologists represent a coalition of professions united by their shared mission and focus on disease prevention and health promotion. As part of their prevention efforts, epidemiologists search for common exposures and shared characteristics among people who are sick or affected by drug use and addiction to seek causative measures. More specifically, public health experts, use a five-step approach to address health problems in the community. They seek to: (1) define the health problem, (2) identify the risk factors associated with the problem, (3) develop and test community level intervention to control or prevent the cause of the problem, (4) implement interventions to improve the health of the population, and (5) monitor the interventions to assess their effectiveness (Schneider, 2011, p11-12). These measures are used to develop interventions to prevent undesirable health outcomes that have been identified either via surveillance by health officials or from community concerns related to health matters such as an increasing number of opioid addicts (including pregnant women).

Public health officials, as well as epidemiologists employ a systematic approach to address health problems. They design strategies of intervention to prevent undesirable health outcomes. They typically prevent illnesses and accidents by using a three-prong approach that includes: Primary prevention, secondary prevention, and tertiary prevention. First, primary prevention seeks to avoid the illness or occurrence by preventing exposure to risk factors. This occurs when health officials inform women about substance and opioid misuse before pregnancy. Moreover, it seeks to reduce the abuse of prescription opioids via monitoring, ensuring that unused opioids are disposed of and provide police with tools needed to stop illegal prescription writing. Public health officials typically engage in educational campaigns by using television, radio, and billboards to warn the public about the dangers associated with prescription and illegal opioids (e.g., heroin). For example, they may target $O U D, H I V / A I D S, H C V, N A S$, or other consequences from engaging in risky behavior. Next, secondary prevention seeks to minimize the severity of the illness or damage due to the injury causing event after it has occurred. This occurs when health officials provide opioid users the treatment they need before they become addicted to prescription or illegal heroin which could produce negative health consequences for pregnant women, as well as their unborn child. This effort may require early identification of illicit substance use during pregnancy. It is necessary to improve the health outcomes for mothers and their unborn infants. Experts also recommend the use of routine screening for drug use during pregnancy. Finally, tertiary prevention focuses on minimizing disability by providing medical care and rehabilitation services (Schneider, 2011, p12). Because pregnant women with OUD often face preterm labor, fetal distress, or fetal death, health providers argue they should be given opioid agonist therapy or medication assisted treatment with methadone or buprenorphine since it is considered as standard treatment. These treatments help mothers and infants by: stabilizing fetal levels or opioids, reduce repeated prenatal withdrawal, bring mothers inline for treatment of infectious disease such as $H I V, H B V, H C V$, and reduce the likelihood of transmitting these to unborn infants, and ultimately, improving the long-term health outcomes for both mother and baby (NIH, 2017). Public health officials are committed to providing treatment to pregnant women, their unborn infants, and others who may have an illness linked to legal or illegal opioids.

\section{Prevention and Treatment}

Healthcare experts suggest that successful efforts at preventing and reducing incidence of NAS can be achieved as part of primary prevention strategies. According to Ko and colleagues (2017), primary prevention techniques to prevent NAS must focus on a twofold approach: responsible opioid prescribing and providing users with access to preconception care and family planning services. First, where responsible opioid prescribing is concerned, experts at the $C D C$ recommend that clinicians be aware of the sensitive nature of prescribing opioid medications to pregnant and nonpregnant women at reproductive age. Furthermore, the $C D C$ recommends that clinicians disclose the long-term effects of opioid use to patients with regard to their current and future pregnancy. Similarly, Dowell, Haegerich, \& Chou 
(2017), reported that the $C D C$ has issued guidelines specifying a protocol that clinicians should follow when prescribing opioids to pregnant women. One recommendation is that clinicians and patients fully consider the risks and benefits before deciding whether to use opioid therapy for chronic pain during pregnancy. Another recommendation is that women of reproductive age strongly consider using nonopioid pharmacologic therapy to manage chronic pain. The CDC also advises that when opioids are used, clinicians should prescribe the lowest effective dosage (Dowell et al., 2017). Second, family planning services are also recommended as a primary prevention strategy that might help prevent and reduce incidence of $N A S$ (Gavin et al., 2014). Research shows that the $C D C$ recommends that access to family planning and preconception care is provided to women of reproductive age. In their investigation, Gavin and colleagues (2014), found that among women who abused opioids, 86\% reported that their pregnancy was unplanned. Because of this, public health officials at the CDC and the Office of Population Affairs of the U.S. Department of Health and Human Services recommend that healthcare providers encourage the use of family planning services that offer an array of options that include: preconception services, pregnancy intervention screening, and contraceptive counseling to prevent unintended pregnancy.

Health officials suggest that women with $O U D$ (including pregnant women), can be provided intervention treatment strategies. As such, the Substance Abuse and Mental Health Services Administration and the American College of Obstetricians and Gynecologists recommend that pregnant women who suffer from OUD begin medication for addiction treatment (MAT) with methadone or buprenorphine. These same officials argue that both therapies have been shown to be safe and effective treatments for pregnant women who suffer from OUD (see Jones et al., 2018; Klaman et al., 2017). While this is suggested, health officials warn that clinicians should evaluate the effects of concurrent substance use (Smith, Costello, \& Yonkers, 2015). Moreover, they advise that because the likelihood is greater that these women will give birth to babies with NAS (though it is less severe than in the absence of treatment), they should seek collaboration with pediatric care teams to determine if infants suffered utero opioid exposure so that appropriate treatments can be provided (Smith et al., 2015; Klaman et al., 2017).

Health experts report the effects of $N A S$ can be mitigated with the appropriate strategies. For example, some health officials suggest that mitigation can be achieved through improvements in identifying infants who are at risk and standardizing the treatment process of infants with NAS. For example, Ko and colleagues (2017), reported that states such as Florida, Tennessee, Kentucky, and Georgia are leading the way in this effort since they require that all cases of $N A S$ are quickly reported to the state health department. Health experts believe that this strategy will enable states to identify and provide interventions to access locations where high incidence of NAS are reported. Consequently, this will mitigate the effects of $N A S$ and reduce the economic burden associated with them.

Research suggests that treating NAS should start with nonpharmacological strategies that include: minimizing environmental stimuli, careful swaddling, and breastfeeding (when no other contraindications are used) (see Hudak and Tan, 2012). Moreover, to ease the infants' withdrawal from severe cases of $N A S$, some health professionals and the American Academy of Pediatrics recommend tapered dosages of morphine or methadone be used in conjunction with nonpharmacological strategies (Hudak and Tan, 2012). In addition, other research suggests that the use of family involvement or "rooming" with $N A S$ infants instead of placing them in neonatal intensive care units can decrease the length of hospital stays needed for pharmacological treatment (Patrick et al., 2016). Additionally, in a meta-analysis, Klaman and colleagues (2017), used data from three separate search methods to: (1) identify peer reviewed journal articles that focused on evidence of treatment methods for pregnant or nonpregnant women with opioid use disorder $(O U D)$. They excluded from the analysis: (1) review articles that focused on primary publication, (2) commentaries, and (3) articles that did not focus on opioid use and misuse among pregnant women, or those that did not provide the effects of prenatal $O U D$ on children. More specifically, the analysis examined studies that were conducted from 1975 to 2015. A total of 75 articles $(n=75)$ were used to identify evidence regarding treatment given to pregnant and parenting women with $O U D$ and its effect on their infants and children. The authors stated that most of the literature addressed the use of methadone and buprenorphine. The study focused on three areas: (1) prenatal, (2), postnatal, and (3) neonatal. In the final analysis, the study revealed that buprenorphine treatment of $O U D$ during pregnancy resulted in lower risk of preterm births, greater weight, and larger head circumference compared with the use of methadone treatment. Despite this finding, the study suggested that ongoing research on the prenatal, postnatal, and neonatal periods is needed to better understand the complexity of treating $O U D$ among pregnant and nonpregnant women.

In another research investigation by Jones and colleagues (2008), that addressed questions faced by clinicians confronted with treating pregnant patients addicted to opioids, the study reports that much has been learned about treating this special population in the last forty years since clinicians now prescribe both methadone and buprenorphine to these patients. They concluded that methadone maintenance, more so than medication-assisted withdrawal is more effective at preventing relapse since it reduces fetal exposure to illicit drug use and neonatal outcomes. In the end, they argued that the Maternal Opioid Treatment Human Experiment Research (MOTHER) study that began in 2005 which 
compares the safety and efficacy of methadone and buprenorphine provides more evidence-based data needed to guide optimal treatment approaches for opioid dependent pregnant patients.

\section{Policy Implications}

Because the opioid epidemic affects the entire nation, treatment and prevention efforts must be initiated at the local, state, and federal levels by policy-makers and elected officials (Krans and Patrick, 2016). Realizing the enormity of the problem, especially the negative health consequences such as addiction, birth defects, and untimely deaths, the House of Representatives recently passed the Substance Use-Disorder Prevention that Promotes Opioid Recovery and Treatment (SUPPORT) for Patients and Community Act to fight the opioid crisis. The bill specifies that monies should be allocated in several areas that include: (1) expanding access to treatment and recovery services; (2) creating opioid alternatives to pain treatment, and (3) intercepting illegal opioids at mail facilities and combating fentanyl. This bill, along with $\$ 5$ billion from the Comprehensive Addiction and Recovery Act and the 21st Century Cure Act (2016) are steps in the right direction to combat the current drug war. Now, the bill must pass through the Senate and be signed by the President in order to become law. Hopefully, funding from these two sources will be received on the local and state levels and used for providing treatment and therapy to those adversely affected by prescription and illegal opioids (including pregnant addicts). Moreover, health experts report that studies reveal that the epidemic proportions of opioid cases, including addicted pregnant women and increases in NAS cases have come to the attention of healthcare providers, the public, and policy-makers (Patrick and Schiff, 2017). As a result, health experts recommend that policies created to help opioid addicts in general, and addicted pregnant women in particular, should be designed to increase accessibility and affordability of substance abuse treatment services since research reports that access to treatment for maternal OUD and standardized treatment for infants with NAS could help decrease the effects of NAS (Ko et al., 2017).

Our policy recommendations are sevenfold and consistent with those provided by Patrick and Schiff (2017, p4). They include the following: (1) educating the public about the addictive and dangerous potential of prescription and illegal opioid use, namely heroin (e.g., addiction and other risky behaviors), (2) providing evidence-based treatment to pregnant women who suffer from substance abuse disorder, (3) increasing access to reproductive health services, (4) implementing early universal substance screening for all pregnant women (in order to early identify anomalies in the fetus, (5) providing access to improved prenatal care for pregnant women with substance use disorders (to include medication-assisted treatment programs such as methadone or buprenorphine), and gender specific substance treatment programs, (6) informing healthcare providers (who care for women about states mandatory reporting laws' regarding drug use and pregnancy, and (7) allocating appropriate funds for social support services and child welfare systems charged with providing care to infants who are exposed to substances. We argue that these policies will effectively address opioid addicted pregnancies as a public health issue.

Consistent with the public health approach, we recommend the use of the epidemiological or multidisciplinary approach to treating and preventing opioid use and its consequences among pregnant women. As such, we argue that long-term follow-ups with this special population of opioid abusers should involve medical, developmental, and social service agencies. We believe that a coordinated multidisciplinary approach is more likely to improve the health outcomes for infants and mothers than punitive criminal justice responses since this methodology has achieved success with other health problems in the past (Also see $A C O G$, 2017).

At the same time, efforts need to be made nationally to decriminalize pregnant women who are addicted to opioids (Kremer and Arora, 2015). As revealed in this investigation, it is common knowledge that many pregnant opioid addicts are willing to risk their health and the lives of their unborn children to avoid being punished by the justice system. These women typically fear being sent to prison or having their children legally removed from their custody after birth. Thus, this punitive measure is believed by some experts to exacerbate the problems faced by opioid addicted pregnant women. To that end, creating the aforementioned health policies will require a paradigm shift from thinking about opioid addicted women as drug abusers to accepting the National Institute on Drug Abuse's (NIDA) definition of addiction as a chronic disease that can be successfully treated and managed (NIDA, 2010). Stated differently, pregnant opioid addicts must be viewed as women with a treatable disease who need treatment and not punishment. More specifically, NIDA also advises that treating substance use disorders successfully requires social support, patient-provider rapport, and access to treatment.

\section{References}

ACOG Committee on Health Care for Underserved Women (2012). American Society of Addiction Medicine. ACOG committee opinion no. 524: opioid abuse, dependence, and addiction in pregnancy. Obstet Gynecol, 119, 1070-1076. https://doi.org/10.1097/AOG.0b013e318256496e

ACOG Committee Opinion (2017). Opioid use and opioid use disorder in pregnancy. The American Society of Addiction Medicine, 711, 1-14. 
Ailes, E. C., Dawson, A. L., Lind, J. N., Gilboa, S. W., Frey, M. T., Broussard, C. S., \& Honein, M. A. (2015). Opioid prescription claims among women of reproductive age-Unites States, 2008-2012. Morbidity and Mortality Weekly Report, 64(2), 37-41.

Alcabes, P., \& Friedland, G. F. (1995). Injection drug use and human immunodeficiency virus infection. Clinical Infections Diseases, 20, 1467-1479. https://doi.org/10.1093/clinids/20.6.1467

Bagley, S. M., Wachman, E. M., Holland, E., \& Brogly, S. B. (2014). Review of the assessment and management of neonatal abstinence syndrome. Addiction Science \& Clinical Practice, 9, 19. https://doi.org/10.1186/1940-0640-9-19

Bianchi, D. W. (2017). NIH-led workshop addresses opioid misuse during pregnancy: experts identify research gaps and opportunities to improve outcomes for families. National Institute of Health. https://medicalxpress.com/news/2017-06-nih-led-workshop-opioid-misuse-pregnancy.html

Bishop, D., Borkowski, L., Couillard, M., Allina, A., Baruch, S., \& Wood, S. (2017). Bridging the divide white paper: Pregnant women and substance use: Overview of research \& Policy in the United States. Jacobs Institute of Women's Health, The George Washington University.

Bloom, B., \& Owen, B. (2002). Gender responsive strategies: Research, practice, and guiding principles for women offenders. National Institute of Corrections, 2002. http//static.nicic.giv/library/018017

Brocato, C. L. (2015). Effective management of opioid addiction in pregnancy. Clinical Advisor. https://www.clinicaladvisor.com

Calhound, S., Messina, N., Cartier, J., \& Torres, S. (2010). Implementing gender responsive treatment for women in prison: Client and staff perspectives. Federal Probation, 74(3), 27-33.

Centers for Disease Control and Preventions (2015). Outbreak of recent HIV and HCV infections among persons who inject drugs. http/www.bt.cdc.gov/han/han/00377.asp

Centers for Disease Control and Preventions (2016). Increases in drug and opioid overdose deaths-United states, 2000-2014. Morbidity and Mortality Weekly Report, 64(50), 1378-1382.

Centers for Disease Control and Preventions (2016). Vital signs: prescriptions painkillers overdose a growing epidemic, especially among women. Available at http: //www.cdc.gov/vitalsigns/prescriptionpainkillers overdoses

Centers for Substance Abuse Treatment (1997). Substance abuse treatment for incarcerated women offenders: Guide to promising practices. Rockville, MD: Department of Health and Human Services, Public Health Services, p2.

Chesney, Lind, M., \& Pasko, L. (2004). The female offender: Girls, women and crime. Thousand Oaks, CA: Sage.

Cicero, T.J., Ellis, M.S., Surratt, H.L., \& Kurtz, S.P. (2014). The changing face of heroin use in the United States: A retrospective analysis of the past 50 years. JAMA Psychiat, 71(7), 821-826. https://doi.org/10.1001/jamapsychiatry.2014.366

Cohen, R. (2017). Pregnant users need treatment, not jail. www.reuters.com/article/us-health-addicts-pregnant

Covington, S. (2007). Women and the criminal justice system. Washington, D.C.: Jacobs Institute of Women Health.

Craig, C. R., \& Stitzel, R. E. (1994). Modern pharmacology ( $4^{\text {th }}$ ed.). New York: Little, Brown and Company.

Desai, R. J., Hernandez-Diaz, S., Bateman, B. T., \& Huybrechts, K. F. (2014). Increase in prescription opioid use during pregnancy among Medicaid-enrolled women. Obstet Gynecol, 123, 1158-1165. https://doi.org/10.1097/AOG.0000000000000208

Dowell, D., Haegerich, T. M., \& Chou, R. (2016). CDC guidelines for proscribing opioids for chronic gain - United States, 2016. JAMA, 315(15), 1624-1645. https://doi.org/10.1001/jama.2016.1464

Farst, K. J., Valentine, J. L., \& Hall, R. W. (2011). Drug testing for newborn exposure to illicit substances in pregnancy: pitfalls and pearls. International Journal of Pediatrics. http://dx.doi.org/10.1155/2011/ 951616

Gaines, L. K., \& Kraska, P. B. (1997). Drugs, crime, and justice: Contemporary Perspectives. Prospect Heights, IL: Waveland Press.

Gavin, L., Moskosky, S., \& Carter, M. (2014). Providing quality family planning services: Recommendations of CDC and the US Office of Population Affairs. Morbidity and Mortality Weekly Report, 63(4), 1-54.

Greenfield, L. A., \& Snell, T. L. (1999). Women offenders. Bureau of Justice Statistics Special Report. Washington, D.C.

Harvey, R. A., Champe, P. C., Mycek, M. J., Gertner, S. B., \& Perper, M. M. (Eds.). (1992). Lippincott's illustrated reviews: Pharmacology. New York: J.B. Lippincott Company. 
Hudak, M. L., \& Tan, R. C. (2014). The committee on drugs and the committee on fetus and newborn. Neonatal drug withdrawal. Pediatrics, 133(5), 540-560.

Hunter, L. (2017). Pregnant addicts need help, not jail. www.newsobserver.com/opinion/op-ed/article.186355398. html

Jones, H. E., Martin, P. R., Heil, S. H., Kaltenbauch, K., Selby, P., Coyle, M. G., .. Fischer, G. (2008). Treatment of opioid-dependent pregnant women: Clinical and research issues. Journal of Substance Abuse Treatment, 35, 245-259. https://doi.org/10.1016/j.jsat.2007.10.007

Jones, H., Johnson, R., Jasinski, D., O Grady, K., \& Chisolm, C. (2005). Buprenorphine versus methadone in the treatment of pregnant opioid-dependent patients: Effects on the neonatal abstinence syndrome. Drug and Alcohol Dependence, 79, 1-10. https://doi.org/10.1016/j.drugalcdep.2004.11.013

Kaeble, D., \& Cowling, M. (2018). Correctional populations in the United States, 2016. U.S. Department of Justice, Office of Justice Programs. www.ojp.usdo.gov.

Karberg, J. C., \& James, D. L. (2005). Substance dependence, abuse and treatment of jail inmates, 2002. Washington, D.C.: U.S. Department of Justice, Bureau of Justice Statistics Bulletin, p10.

Klaman, S. L., Isaacs, K., Leopold, A., Perpich, J., Hayashi, S., Venders, J., ... Jones, H.E. (2017). Treating women who are pregnant and parenting for opioid use disorder and the concurrent care of their infants and children: Literature review to support national guidance. $J$ Addict Med, $11(3), \quad$ 178-190. https://doi.org/10.1097/ADM.0000000000000308

Ko, J. Y., Patrick, S. W., Tong, V. T., Patel, R., Lind, J. N., \& Barfield, W. D. (2016). Incidence of neonatal abstinence syndrome-28 States, 1999-2013. Morbidity and Mortality Weekly Report, 65(9), 799-802. https://doi.org/10.15585/mmwr.mm6531a2

Ko, J. Y., Wolicki, S., Barfield, W. D., Patrick, S. W., Broussard, C. S., Yonkers, K. A., Naimon, R., \& Iskander, J. (2017). CDC Grand Rounds: Public Health Strategies to Prevent Neonatal Abstinence Syndrome. Morbidity and Mortality Weekly Report, 66(9), 242-245. https://doi.org/10.15585/mmwr.mm6609a2

Krans, E. E., \& Patrick, S. W. (2016). Opioid use disorder in pregnancy: Health policy and practice in the midst of an epidemic. Obstet Gynecol, 128(1), 4-10. https://doi.org/10.1097/AOG.0000000000001446

Krans, E. E., Zickmund, S. I., Rustgi, V. K., Park, S. Y., Dunn, S. L., Schwarz, E. B., \& Patrick, S. W. (2015). Screening and evaluation of hepatitis $\mathrm{c}$ virus infection in pregnant women on opioid maintenance therapy: A retrospective cohort study. Subst Abuse, 16, 1-8.

Kremer, M. E., \& Arora, K. S. (2015). Clinical, ethical, and legal considerations of pregnant women with opioid abuse. Obstet Gynecol, 126(3), 474-478. https://doi.org/10.1097/AOG.0000000000000991

Krisberg, B., Marchionna, S., \& Hartney, C. (2015). American corrections: Concepts and controversies. Thousand Oaks, CA: Sage.

Maeda, A., Bateman, B. T., Clancy, C. R., Creanga, A. A., \& Leffert, L. R. (2014). Opioid abuse and dependency during pregnancy: temporal trends and obstetrical outcomes. Anesthesiology, 121, 1158-1165. https://doi.org/10.1097/ALN.0000000000000472

Mauer, M. (2006). Race to incarcerate ( $2^{\text {nd }}$ ed). New York, NY: The New Press.

McCance-Katz, E. F. (2011). Drug interactions associated with methadone, buprenorphine, cocaine, and HIV medications: Implications for pregnant women. Life Sci, 88(21-22), 953-958. https://doi.org/10.1016/j.lfs.2010.09.016

McCance-Katz, E. F., Sullivan, L. S., \& Nallani, S. (2009). Drug interactions of clinical importance between the opioids, methadone, buprenorphine, and frequently prescribed medications: A review. American Journal of Addiction, 19, 4-16. https://doi.org/10.1111/j.1521-0391.2009.00005.x

Messner, S. F., \& Rosenfeld, R. (2013). Crime and the American dream ( $5^{\text {th }}$ ed.). Belmont, CA: Thomson/Cengage Learning.

Mumola, C. C., Karberg, J. C. (2006). Druguse and dependence, state, and federal prisoneers,2004. Bureau of Justice Statistics Special Report. Washington, D.C.: U.S. Department of Justice, p3.

National Institute of Drug Abuse. (2015). Drugs of Abuse: Opioids. Bethesda, MD: National Institute on Drug Abuse. Available at http://www.drugabuse.gov/drugs-abuse/opiods

National Institute on Drug Abuse. (2010). The science of addiction: National Institute of Health. Bethesda, MD.

NIH (2017). Treating opioid use disorders during pregnancy. National Institute on Drug Abuse. www.drugabuse.gov 
Paltrow, L. M., \& Flavin, J. (2013). Arrests of and forced interventions on pregnant women in the United States, 1973-2005: Implications for women's legal status and public health. J. Health Polit Policy Law, 38(2), 299-343. https://doi.org/10.1215/03616878-1966324

Patrick, S. W., \& Schiff, D. M. (2017). A public health response to opioid use in pregnancy. American Academy of Pediatrics, 139(3), 1-7. https://doi.org/10.1542/peds.2016-4070

Patrick, S. W., Davis, M. M., Lehmann, C. U., \& Cooper, W. O. (2015). Increasing incidence and geographic distribution of neonatal abstinence syndrome: United States 2009 to 2012. J Perinatal, 35, 650-655. https://doi.org/10.1038/jp.2015.36

Patrick, S. W., Schumacher, R. E., Benneyworth, B. D., Krans, E. E., McAllister, J. M., \& Davis, M. M. (2012). Neonatal abstinence syndrome and associated health care expenditures: United States 2000-2009. JAMA, 307, 1934-1940. https://doi.org/10.1001/jama.2012.3951

Patrick, S. W., Schumacher, R. E., Horbar, J. D., Buus-Frank, M., Edwards, E. M., Morrow, K. A., ... Soll, R. F. (2016). Improving care for neonatal abstinence syndrome. Pediatrics, 137(5), 1-10. https://doi.org/10.1542/peds.2015-3835

Peak, K. J., \& Everett, P. M. (2017). Introduction to criminal justice: Practice and process ( $2^{\text {nd }}$ ed). Thousand Oaks, CA: Sage.

Reddy, U. M., Davis, J. M., Ren, Z., \& Greene, M. F. (2017). Opioid use in pregnancy, neonatal abstinence syndrome, and childhood outcomes. Obstetrics \& Gynecology, 130(1), 10-28. https://doi.org/10.1097/AOG.0000000000002054

Roberts, S. C., \& Nuru-Jeter, A. (2010). Women's perspectives on screening for alcohol and drug use in prenatal care. Women Health Issues, 20(3), 193-200. https://doi.org/10.1016/j.whi.2010.02.003

Rosenberg, M. L., \& Fenley, M. A. (1991). Violence in America: A public health approach. New York, NY: Oxford University Press.

Rudd, R. A., Aleshire, N., Zibbell, J. E., \& Gladden, R. M. (2016). Increases in drug and opioid overdose deaths-United States, 2000-2014. Morbidity and Mortality Weekly Report, 64, 1378-1382. https://doi.org/10.15585/mmwr.mm6450a3

Schneider, M. J. (2002). Introduction to public health. Gaithersburg, MD: Aspen Publisher.

Scruggins, J. R., \& Malley, S. (2010). Reentry and (unmet) needs of women. Journal of Offender Rehabilitation, 49(2), 146-163. https://doi.org/10.1080/10509670903546864

Seiter, R. P. (2014). Corrections an introduction. ( $4^{\text {th }}$ ed.). Upper Saddle River, NJ: Pearson.

Smith, M. V., Costello, D., \& Yonkers, K. A. (2015). Clinical correlates of prescription opioids analgesic use in pregnancy. Matern Child Health J, 19, 548-556. https://doi.org/10.1007/s10995-014-1536-6

Steedman, S. A., \& Younoussi, Z. M. (2000). Hepatitis C: An update on a silent epidemic. J Clin Gastroenterol, 30, 125-143. https://doi.org/10.1097/00004836-200003000-00005

Stephan, J. J. (2008). Census of state and federal correctional facilities, 2005. Washington, DC: U.S. Department of Justice, Office of Justice Programs, Bureau of Justice Statistics.

Swanson, J. (2014). Pregnancy and Addiction Treatment. The Fix, www.thefix.com

Tonry, M., \& Wilson, J. Q. (1990). Drugs and Crime. Chicago: The University of Chicago Press.

Vestal, C. (2017). Expanding the use of civil commitment for people addicted to opioids is gaining ground. http:/www.Herald-Dispatch.com.news

\section{Copyrights}

Copyright for this article is retained by the author(s), with first publication rights granted to the journal.

This is an open-access article distributed under the terms and conditions of the Creative Commons Attribution license which permits unrestricted use, distribution, and reproduction in any medium, provided the original work is properly cited. 